\title{
HEART DISEASE AS THE PRESENTING FEATURE IN MYOTONIA ATROPHICA
}

\author{
BY
}

\section{J. M. HOLT AND EDWARD H. N. LAMBERT}

From the Department of Medicine, Queen's University, Kingston, Canada

Nearly 20 years ago Evans (1944) suggested that the cardiac abnormalities that are associated with myotonia atrophica might in some cases be an important aid to the early diagnosis of this disease. This report concerns a patient who was first thought to be a case of non-specific myocarditis, but who later proved to be one of cardiomyopathy due to myotonia atrophica after a family history of this disease was uncovered.

\section{Case Report}

A 65-year-old woman had an attack of right pleural pain in January 1961, without preceding or subsequent chest symptoms. Her temperature was raised for 24 hours, she had a slow irregular pulse, blood pressure $110 / 70 \mathrm{~mm} . \mathrm{Hg}$, and there were râles at the right base. Cardiomegaly was seen on the radiograph, and atrial fibrillation, low voltage QRS complexes, and low or flat $T$ waves were present in the electrocardiogram. Before this episode she had been well except for tiredness and somnolence during the previous year. Treatment with thyroxine for six weeks had not brought improvement.

On admission to hospital in March 1961, she had no complaints except for the increasing tiredness and loss of energy, but despite these she had been curling during the early winter. She denied having had muscular weakness, shortness of breath, angina, or ankle œdema. Inquiry into her family history had negative results.

Her skin was dry and she had frontal baldness. There was an immature cataract in the left eye. The pulse was irregular and slow and varied in rate from 40 to 65 a minute. The cardiac apex beat was $13 \mathrm{~cm}$. from the mid-line in the fifth intercostal space, and there was a soft systolic murmur at the apex. The blood pressure was $110 / 70$ to $130 / 96 \mathrm{~mm}$. Hg. The electrocardiogram (Fig. 1) showed the changes previously noted and multifocal premature ventricular contractions. Fluoroscopy with barium swallow showed enlargement of all four chambers but especially of the left ventricle. Laboratory investigation included a normal urinalysis, hæmoglobin $14.8 \mathrm{~g} . / 100 \mathrm{ml}$, sedimentation rate $26 \mathrm{~mm}$., serum cholesterol $240 \mathrm{mg}$. $/ 100 \mathrm{ml}$., serum protein-bound iodine $7.6 \mu \mathrm{g} . / 100 \mathrm{ml}$., serum iron $130 \mu \mathrm{g}$. $/ 100 \mathrm{ml}$., negative tests for lupus erythematous cells, anti-streptolysin titre of 12 units, negative latex fixation test, and a negative test for sheep cell agglutinins. The common causes of myocarditis were considered and discarded for lack of supporting evidence. In the end a diagnosis of non-specific myocarditis was made, and she was discharged without treatment.

One week later she was readmitted with a 24-hour history of moderately severe expressive aphasia and weakness of the lower half of the face, and of the arm, hand, and foot on the right side. There were no other new findings, and the electrocardiogram was unchanged. A diagnosis of cerebral embolus was made and she was treated with anticoagulants after her cerebrospinal fluid had been shown to be normal. The neurological symptoms disappeared within a few days. She was then visited for the first time by members of her family. One was a 34-year-old daughter who bore the characteristic facies of myotonia atrophica, which had been diagnosed in her case some years previously. This daughter told also of her brother and a maternal uncle who were also known to have myotonia atrophica.

With this disease in mind, the patient was re-examined and it became clear that she too had myotonia 433 


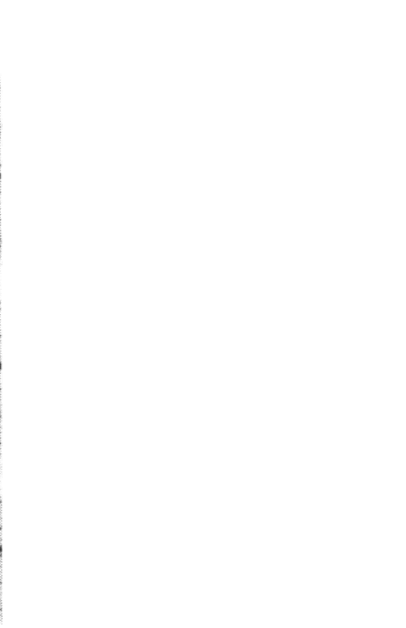

FIG. 1.-Electrocardiogram showing atrial fibrillation with a slow ventricular rate, low voltage QRS complexes, and flat $\mathrm{T}$ waves.

atrophica, but myotonia and muscular atrophy were only minimal. The diagnosis was confirmed by electromyography which showed the typical high frequency "dive bomber" action potentials. Other investigations showed a normal sella turcica, hyperostosis frontalis, normal 24-hour urinary excretion of 17-ketosteroids (3.9 mg.) and of 17-hydroxycorticoids $(6.5 \mathrm{mg}$.). Kymography of the heart showed ventricular movements of normal amplitude.

She recovered fully from the cerebral embolus and was discharged from hospital on anticoagulant treatment with a diagnosis of myotonia atrophica with associated cardiomyopathy. She remained well for 14 months during which time her pulse continued to be slow and irregular and her blood pressure varied between $98 / 50$ and $120 / 60 \mathrm{~mm}$. Hg. She continued to deny any symptoms of myotonia but clinically both myotonia and atrophy of the small muscles of the hands became more apparent.

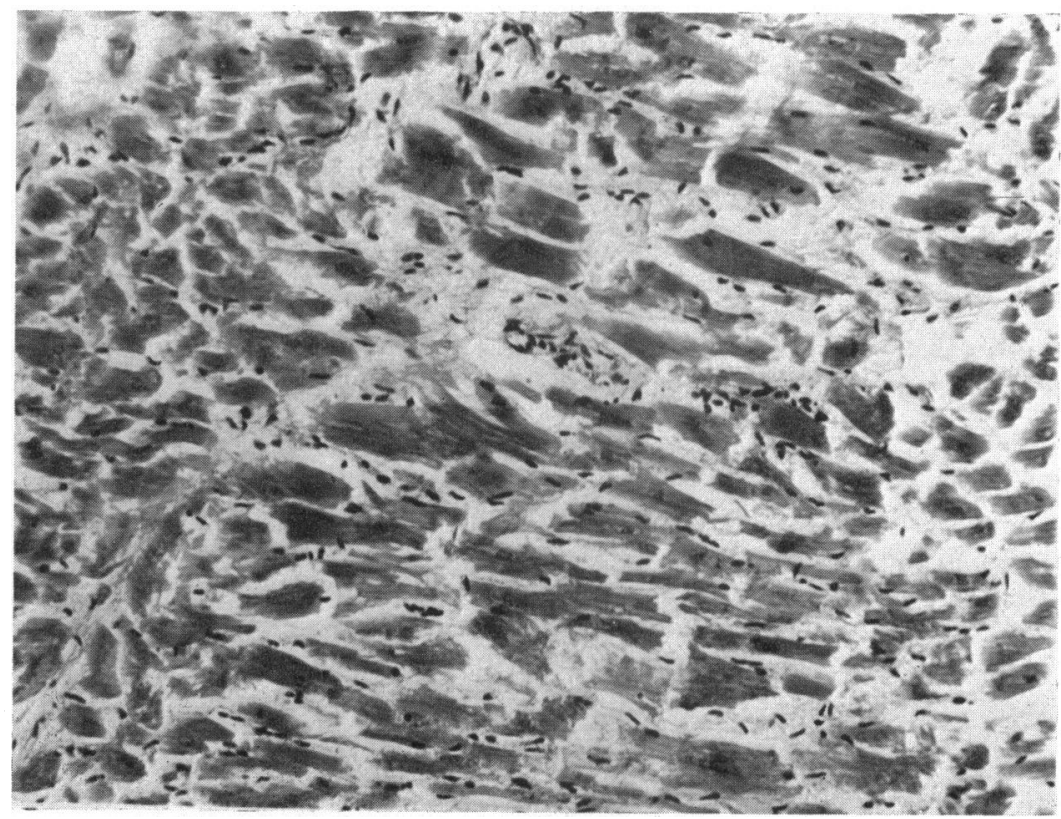

FIG. 2.-Section of myocardium showing diffuse infiltration of the bundles by fat and fibrous tissue. $(\times 100$. 
In August 1962 she died unexpectedly in her sleep. An autopsy was performed about 12 hours after death and it appeared that she had died of acute left heart failure. The heart weighed $450 \mathrm{~g}$. and was diffusely enlarged and dilated. The heart muscle was flabby and the coronary arteries were patent. Microscopically there were areas of fatty infiltration between the myocardial bundles of the right atrium and right ventricle but the bundles themselves were normal (Fig. 2). The sternomastoid muscles were wasted with areas of normal muscle and areas in which the muscle fibres were small and embedded in fibrous tissue. The sarcolemmal nuclei were normal.

\section{Discussion}

Cardiac abnormalities in patients suffering from myotonia atrophica have been frequently reported since attention was first drawn to them by Griffith in 1912. A review of cases that have been reported since that time shows that there are some characteristic features of this type of heart disease. About 40 per cent of patients show conduction defects in their electrocardiograms with varying degrees of atrio-ventricular block and intraventricular block. Atrial fibrillation and flutter are not uncommon. About 25 per cent of cases have a systolic blood pressure under $110 \mathrm{~mm} . \mathrm{Hg}$ and about 20 per cent have bradycardia with a heart rate of less than 60 beats a minute. Some degree of cardiomegaly occurs in about 15 per cent of cases. This patient illustrated most of these features, having atrial fibrillation, a slow pulse, a low blood pressure at times, and an enlarged heart.

Evans (1944) remarked that the recognition of the cardiac abnormalities might be found in the future to be important as an aid to the early diagnosis of myotonia atrophica. Fisch (1951) reviewing 85 reported cases found that in only 6 were cardiac symptoms the chief presenting complaints, and in all of them major neuromuscular manifestations had preceded the onset of cardiac symptoms by some time. Spillane (1951) in 16 cases also found that neuromuscular defects had been invariably apparent long before there were any symptoms or signs of heart disease. The same was true of cases reported by Cantwell and Hickey (1954), Kilburn, Eagen, and Heyman (1959), Gordin et al. (1960), and Slatt (1961). However, Litchfield (1953) described a case with severe heart involvement characterized by frequent Stokes-Adams attacks in which neuromuscular manifestations were asymptomatic and of minor importance; the electrocardiogram showed a varying atrio-ventricular block. Cannon (1962) in a report of 11 cases also described two patients in whom cardiovascular symptoms had antedated neuromuscular complaints; both had presented with arrhythmia.

There are few reports on the histology of the myocardium in myotonia atrophica. Keschner and Davison (1933) described one case that showed fatty infiltrations into both ventricular walls. Black and Ravin (1947) found no remarkable histology in 5 cases brought to autopsy. Fisch and Evans (1954) described a case that showed fatty infiltration into the left atrium and generalized interstitial fibrosis with separation of muscle fibres some of which were hypertrophied and contained large rectangular nuclei. One of the cases described by Cannon (1962) had normal histology at autopsy and a second showed focal areas of interstitial fibrosis with marked variation in the size of muscle fibres, some atrophied or necrotic and some hypertrophied. There was variation in the size of the nuclei. He considered these changes to be of the type described by Fisch and Evans (1954). Slatt (1961) described one case with diffuse interstitial fibrosis.

It seems, therefore, that there is not always a characteristic histological pattern in these cases but that a varying amount of myocardial replacement with fat or fibrous tissue may occur. There is not a close relation between the severity of the changes seen in the heart and those seen in skeletal muscle, and histological description does not bear a close relation to the clinical severity of the cardiopathy. In the case reported here only minimal histological changes were apparent yet the heart involvement was by far the most serious aspect of her disease.

\section{Summary}

An unusual case of myotonia atrophica is described in which the cardiac abnormalities predominated. The histological changes found at autopsy were non-specific and, like those previously reported, fail to throw light on the mechanism of this type of heart disease. 
We wish to thank Dr. G. M. Brown, Professor of Medicine, Queen's University, for his help and encouragement in the preparation of this paper.

\section{References}

Black, W. C., and Ravin, A. (1947). Studies in dystrophia myotonica. VII. Autopsy observations in five cases. Arch. Path., 44, 176.

Cannon, P. J. (1962). The heart and lungs in myotonic muscular dystrophy. Amer. J. Med., $32,765$.

Cantwell, D. F., and Hickey, K. M. (1954). Dystrophia myotonica with cardiac symptoms. Irish J. med. Sci., sixth series, p. 360.

Evans, W. (1944). The heart in myotonia atrophica. Brit. Heart J., 6, 41.

Fisch, C. (1951). The heart in dystrophia myotonica. Amer. Heart J., 41, 525.

and Evans, P. V. (1954). The heart in dystrophia myotonica. New Engl. J. Med., 251, 527.

Gordin, R., Koskenoja, M., Lamberg, B. A., Lindqvist, C., Olin-Lamberg, C., and Pihkanen, T. (1960). Myotonic dystrophy. Report of five cases. Acta med. scand., 166, 151.

Griffith, T. W. (1912). On myotonia. Quart. J. Med., 5, 229.

Keschner, M., and Davison, C. (1933). Dystrophia myotonica. Arch. Neurol. Psychiat. (Chic.), $30,1259$.

Kilburn, K. H., Eagen, J. T., and Heyman, A. (1959). Cardiopulmonary insufficiency associated with myotonic dystrophy. Amer. J. Med., 26, 929.

Litchfield, J. A. (1953). A-V dissociation in dystrophia myotonica. Brit. Heart J., 15, 357.

Slatt, B. (1961). Myotonia dystrophia-a review of 17 cases. Canad. med. Ass. J., 85, 250.

Spillane, J. D. (1951). The heart in myotonia atrophica. Brit. Heart J., 13, 343. 